\title{
CARACTERIZAÇÃO GEOLÓGICA, GEOMORFOLÓGICA E PEDOLÓGICA DE PATOS DE MINAS (MG): CONTRIBUIÇÃO À INTERPRETAÇÃO DAS FEIÇÕES EROSIVAS
}

\author{
Raul Rassi ${ }^{(a)}$, Rayanne Lina Bicalho ${ }^{(\mathrm{b})}$, Juliana Abreu Crosara Petronzio $^{(\mathrm{c})}$, Alan Silveira $^{(\mathrm{d})}$ \\ (a) Discente do curso de Geologia da UFU, campus Monte Carmelo, raul_rassi@ hotmail.com \\ (b) Discente do curso de Geologia da UFU, campus Monte Carmelo, rayanne.bicalho@ufu.br \\ ${ }^{\text {(c) }}$ Técnica do Instituto de Geografia (IG UFU), curso de Geologia campus Monte Carmelo, \\ julianapetronzio@ufu.br \\ ${ }^{(\mathrm{d})}$ Docente do Instituto de Geografia (IG UFU), curso de Geologia campus Monte Carmelo, alan.silveira@ufu.br
}

\section{EIXO: SISTEMAS GEOMORFOLÓGICOS: ESTRUTURAS, DINÂMICAS E PROCESSOS}

\begin{abstract}
Resumo
O trabalho apresenta os resultados identificados a partir da caracterização geológica, pedológica e geomorfológica de Patos de Minas (MG), a fim de contribuir para o diagnóstico ambiental da área. $\mathrm{O}$ trabalho foi organizado a partir de levantamentos bibliográficos e cartográficos e realização de trabalhos de campo para averiguação dos dados levantados. O domínio geológico é marcado pelas Coberturas Detríticas Cenozoicas Indiferenciadas sobrepostas à Formação Serra da Saudade. Foi observada a fragilidade erosiva da Formação Neoproterozoica, sobretudo no contato com a cobertura de superfície, e que, por vezes neste contato há a presença de nódulos e concreções ferruginosas, mais resistentes ao escoamento superficial. A referida fragilidade erosiva é inerente ao quadro físico-ambiental de Patos de Minas, não só pela litologia frágil, mas também pelo quadro geomorfológico de dissecação, derivado do escoamento concentrado das águas superficiais e pela dinâmica propiciada pelo uso e ocupação de terras, marcada pelo intenso pisoteio do gado.
\end{abstract}

Palavras-chave: caracterização geológica. caracterização pedológica. caracterização geomorfológica. Patos de Minas.

\section{Introdução}

O trabalho apresenta os resultados associados à caracterização regional das condições físicoambientais de Patos de Minas (MG), com o intuito de subsidiar a análise, em fase posterior, de uma área específica, em escala de detalhe. Tal área corresponde ao futuro campus da Universidade Federal de Uberlândia (UFU), o qual se posiciona em área de expansão urbana ao norte desta cidade. Assim, teve por objetivo caracterizar os aspectos geológicos, pedológicos e geomorfológicos de Patos de Minas, com o intuito de contribuir para o diagnóstico ambiental da área, o qual subsidiará as decisões do Grupo de Trabalho Técnico do Plano Diretor (GTTPD/UFU). Procura, portanto, investigar as características físicas e ambientais mencionadas para colaborar com o estabelecimento das diretrizes de uso e ocupação. A princípio, destaca-se que a região de Patos de Minas apresenta uma quantidade significativa de feições erosivas, sobretudo as lineares, com o registro de sulcos erosivos, ravinas e voçorocas. 


\section{Metodologia}

O trabalho apresentou duas etapas de pesquisa, a saber: gabinete e trabalho de campo. No gabinete procedeu-se o levantamento de dados bibliográficos e cartográficos, os quais contemplam a caracterização dos três aspectos analisados: geológicos, pedológicos e geomorfológicos. Para análise geológica foram utilizados a Carta Geológica da Folha Patos de Minas (CPRM, 2013), assim como os trabalhos de Batista (2004), Signorelli (2008) e Machado e Silva (2010), os quais especializam e descrevem as Unidades, Grupos e Formações geológicas. Na caracterização pedológica, o Levantamento de reconhecimento de média intensidade dos solos da região do Alto Paranaíba organizado por Motta et al (2004) serviu como base da inicial caracterização. Foi ainda complementado com as informações trazidas por Lepsch (2011) e pelo Sistema Brasileiro de Classificação de Solos da EMBRAPA (2006). Para a descrição da geomorfologia regional foi utilizado o Mapa de Compartimentação do Relevo do Estado de Minas Gerais em Padrões de Relevos Agrupados (CPRM, 2010), o qual distingue os padrões de relevo. Posteriormente à aquisição das informações bibliográficas e cartográficas, foram realizados trabalhos de campo com o objetivo de averiguá-las in loco. As observações de campo estiveram registradas em cadernetas de campo, bem como em fotografias ilustrativas.

\section{Resultados}

De acordo com Machado e Silva (2010), no estado de Minas Gerais afloram as seguintes unidades geológicas: o Cráton do São Francisco; a Faixa Brasília; o Orógeno Araçuaí/Ribeira; a Bacia do Paraná; e as Coberturas Colúvio-Aluviais e Eluviais. O município de Patos de Minas se localiza no extremo leste da unidade Cráton do São Francisco, no limite com a unidade Faixa Brasília.

A geologia da região estudada é representada pelo Grupo Bambuí, fazendo-se presente com a Formação Serra da Saudade (CPRM, 2013). Esta Formação ainda é acompanhada de Coberturas Detríticas Cenozoicas Indiferenciadas e pelo Grupo Mata da Corda Indiviso (Mesozoico), o qual é constituído de rochas vulcânicas alcalinas (BATISTA, 2004). A Formação Serra da Saudade constituise de siltitos, arenitos e argilitos (SIGNORELLI et al, 2008). Já as Coberturas Detríticas Cenozoicas Indiferenciadas são marcadas pela presença de sedimentos arenosos, areno-argilosos e argilo-siltosos inconsolidados, com ocorrência local de canga e níveis de cascalho (CPRM, 2013). Tais Coberturas Detríticas Cenozoicas estão localizadas em áreas de topo e alta/médias vertentes, estando sobrepostas à Formação Serra da Saudade, que aflora nas médias/baixas vertentes. Foi observada a fragilidade erosiva da Formação Neoproterozoica, sobretudo no contato com a cobertura de superfície, na qual 
registrou-se a presença de concreções ferruginosas em médias vertentes, como ilustra a figura 1, que apresenta fotos da área estudada.

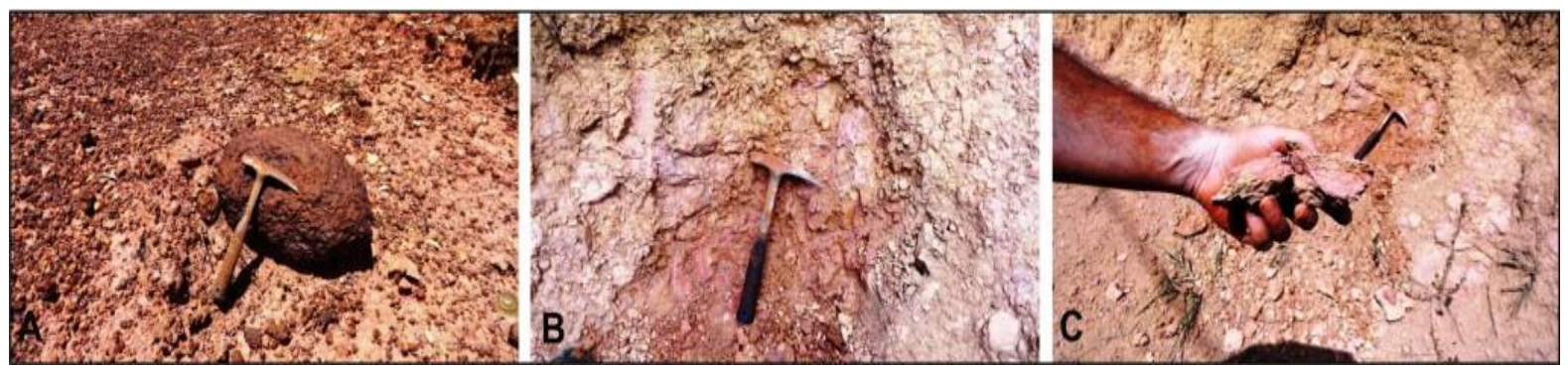

Figura 1 - Nódulos e concreções ferruginosas encontradas em média vertente no norte da cidade de Patos de Minas (1A); Afloramento da Formação Serra da Saudade em média vertente, nas proximidades do campus UFU Patos de Minas (1B); Formação Serra da Saudade em média vertente nas imediações do campus Patos de Minas, com nítida fragilidade erosiva (1C) .

O quadro geomorfológico apontado tanto no mapeamento de Compartimentação do Relevo do estado de Minas Gerais (CPRM, 2010), bem como na análise da fisiografia do Alto Paranaíba elaborada por Motta et al (2004), indicam a marcante presença do Domínio dos Relevos Aplainados. Com base nesses documentos cartográficos e nos trabalhos de campo posteriormente executados, destacam-se para a área ao entorno de Patos de Minas os seguintes padrões de relevos: Superficies Aplainadas Retocadas ou Degradadas - caracterizados por superfícies planas a levemente onduladas, geradas por processo de arrasamento geral do terreno; Relevos Residuais - relevos isolados destacados na paisagem aplainada, remanescentes do arrasamento geral dos terrenos; Planícies Fluviais: planícies de inundação e baixadas inundáveis (CPRM, 2010).

A figura 2 procura ilustrar os 3 padrões de relevo identificados para área, por meio de fotos obtidas em campo. Na foto A observa-se o relevo suave ondulado nas proximidades do campus UFU, que está sendo dissecado pela drenagem. Ao fundo dessa foto, pode-se observar níveis altimétricos mais elevados, caracterizando relevos residuais isolados. Na foto B é ilustrado a área periférica norte da cidade de Patos de Minas, com relevo suave ondulado, onde observa-se o perceptível entalhamento da drenagem. Na foto $\mathrm{C}$, são notados patamares mais elevados e declivosos, caracterizando relevos residuais isolados. Por fim, na foto D é ilustrado a planície de inundação do rio Paranaíba, no setor sul de Patos de Minas.

No âmbito pedológico, os solos predominantes na região de Patos de Minas são classificados como Latossolos. Além desses, há a presença de Cambissolos, Argissolos e Neossolos, assim como afloramentos rochosos expostos. Os Latossolos se caracterizam por estágio avançado de intemperização (EMBRAPA, 2006), com os mais típicos apresentando horizonte A pouco espesso com transição difusa para o B latossólico muito espesso (LEPSCH, 2011). Na região onde se localiza a área destinada ao campus UFU, dominam os Latossolos Vermelhos. 

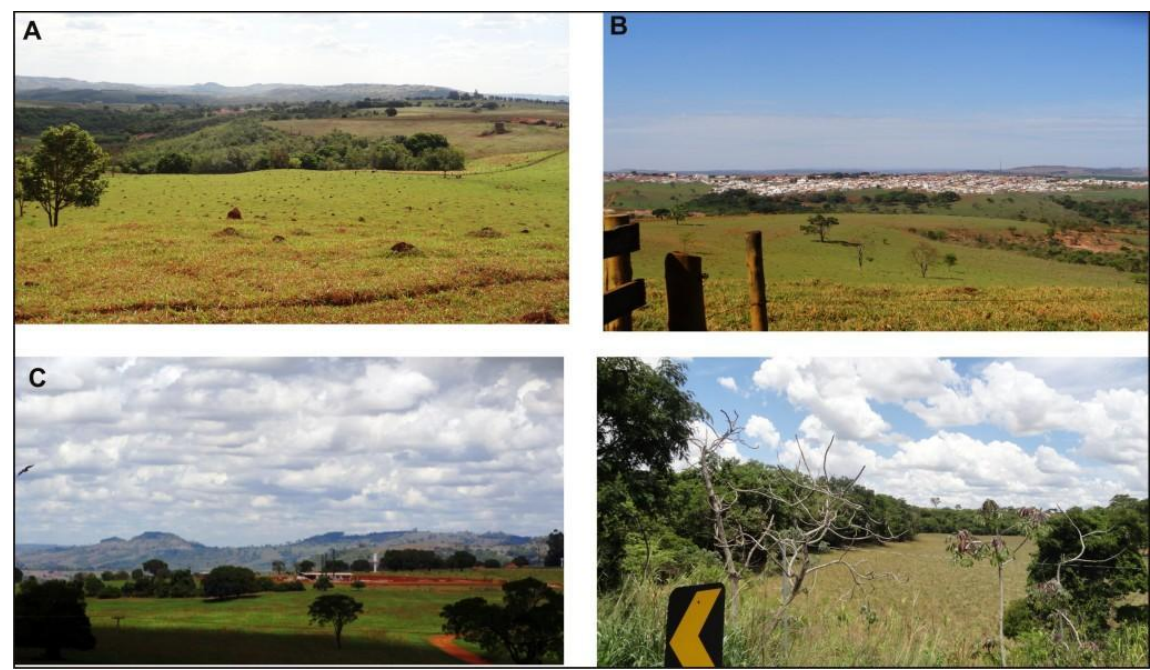

Figura 2 - Fotos ilustrando os padrões de relevo identificados no campo.

Dessa forma, muito embora as características pedológicas indiquem solos profundos e bem desenvolvidos em áreas de topo e terços superiores (figura 3A), foi possível observar um aumento significativo na intensidade dos processos erosivos, posicionados nas altas/médias/baixas vertentes, as quais apresentam ausência ou pouca espessura de solos/Coberturas Detríticas Superficiais, por vezes com nódulos e concreções ferruginosas sobrepostas aos sedimentos da Formação Serra da Saudade, como ilustrado na foto da figura $1 \mathrm{~A}$.

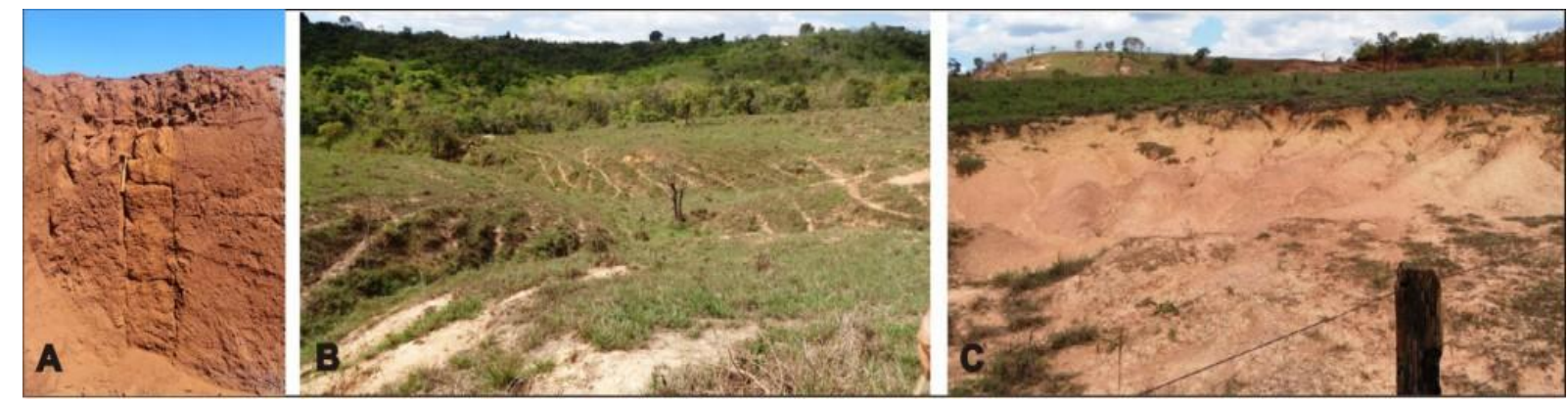

Figura 3 - Latossolo vermelho em setor de topo (3A); marcante pisoteio do gado em área de pastagem (3B); feição erosiva em média vertente de área de pastagem $(3 \mathrm{C})$.

Assim, a suscetibilidade à erosão é inerente ao quadro físico-ambiental de Patos de Minas. A fragilidade do material rochoso representado pela Formação Serra da Saudade (figura 1C) e o contexto geomorfológico relacionado a dissecação do relevo (Superfícies Aplainadas Retocadas ou Degradadas, figuras 2A e 2B), associados à interferência das condições climáticas, nitidamente marcadas pela presença de uma estação chuvosa de verão, sofrem ainda a contribuição da intensa dinâmica propiciada pelo uso e ocupação da terra, a qual é retratada nas figuras 3B e 3C, respectivamente, com o marcante pisoteio do gado e com a feição denudativa em área de pastagem. 


\section{Considerações Finais}

A dinâmica erosiva registrada em Patos de Minas está associada ao contexto de uso e ocupação, dominantemente representado pela pastagem, bem como a fragilidade do material rochoso e o quadro geomorfológico de dissecação. Observa-se que essa dissecação deriva do escoamento concentrado das águas superficiais que entalham a cobertura superficial/solo até atingir o material rochoso da Formação Serra da Saudade, o qual é marcado por elevada fragilidade. Chama-se a atenção para a transição entre cobertura de superfície e a Formação Serra da Saudade, pela presença de nódulos e concreções ferruginosas em médias vertentes, registrados, respectivamente, ao sul da cidade e ao norte de Patos de Minas (nas imediações do campus UFU). Observou-se que a intensa dissecação do relevo erode a Cobertura Superficial Cenozoica e atinge a Formação Serra da Saudade. Neste processo, restam nódulos e concreções, que se configuram mais densos e menos frágeis ao escoamento de superfície em relação aos siltitos, arenitos e argilitos da Formação Serra da Saudade.

\section{Referências Bibliográficas}

BATISTA, M.C. Estratigrafia e Evolução Geológica da Região de Lagoa Formosa. 2004. Dissertação (Mestrado em Geologia) - Instituto de Geociências, Universidade Federal de Minas Gerais (UFMG), 2004.

CPRM, SERVIÇO GEOLÓGICO DO BRASIL. Carta Geológica: Folha de Patos de Minas (SF.23-Y-A-VI), escala 1:100.000, 2013.

CPRM, SERVIÇO GEOLÓGICO DO BRASIL. Mapa dos Domínios Geomorfológicos do estado de Minas Gerais. In: MACHADO, M.F; SILVA, S.F. (Org). Geodiversidade do estado de Minas Gerais. Belo Horizonte: CPRM, 2010.

EMBRAPA, EMPRESA BRASILEIRA DE PESQUISA AGROPECUÁRIA. Sistema brasileiro de classificação de solos. 2a. ed. - Rio de Janeiro : EMBRAPA-SPI,2006.

IBGE, InSTITUTO BRASILEIRO DE GEOGRAFIA E ESTATÍSTICA. Manual Técnico de Pedologia. Rio de Janeiro: IBGE, 2015.

LEPSCH, I. 19 Lições de Pedologia. São Paulo: Oficina de Texto, 2011.

MACHADO, M.F; SILVA, S.F. (Org). Geodiversidade do estado de Minas Gerais. Belo Horizonte: CPRM, 2010.

MOTTA, P. E. et al. Levantamento de reconhecimento de média intensidade dos solos da região do Alto Paranaíba, Minas Gerais. Rio de Janeiro : Embrapa Solos, 2004. 
SIGNORELLI, N; FÉBOLI, W.L; TULLER, M.P; RIBEIRO, J. H. Extensão areal da Formação Serra da Saudade, Grupo Bambuí, para a região centro-sul de Minas Gerais. In: Anais, Repositório Institucional de Geociências, 2008. Disponível em: http://rigeo.cprm.gov.br/xmlui/handle/doc/754.

\section{Agradecimentos:}

Agradecemos o Instituto de Geografia (IG-UFU), o setor de Infraestrutura da Prefeitura Universitária UFU e o Grupo de Trabalho Técnico do Plano Diretor (GTTPD/UFU) pela oportunidade de realização desse trabalho.

Agradecemos o apoio da FAPEMIG que colaborou para a participação neste evento. 